\title{
How much does participatory flood management contribute to stakeholders' social capacity building? Empirical findings based on a triangulation of three evaluation approaches
}

\author{
M. Buchecker ${ }^{1}$, S. Menzel ${ }^{1}$, and R. Home ${ }^{1,2}$ \\ ${ }^{1}$ Swiss Federal Research Institute WSL, Group Social Science in Landscape Research, Zürcherstrasse 111, \\ 8903 Birmensdorf, Switzerland \\ ${ }^{2}$ Research Institute of Organic Agriculture (FIBL), Ackerstrasse 21, 5070 Frick, Switzerland \\ Correspondence to: M. Buchecker (matthias.buchecker@wsl.ch) \\ Received: 30 November 2012 - Published in Nat. Hazards Earth Syst. Sci. Discuss.: - \\ Revised: 5 March 2013 - Accepted: 10 April 2013 - Published: 5 June 2013
}

\begin{abstract}
Recent literature suggests that dialogic forms of risk communication are more effective to build stakeholders' hazard-related social capacities. In spite of the high theoretical expectations, there is a lack of univocal empirical evidence on the relevance of these effects. This is mainly due to the methodological limitations of the existing evaluation approaches. In our paper we aim at eliciting the contribution of participatory river revitalisation projects on stakeholders' social capacity building by triangulating the findings of three evaluation studies that were based on different approaches: a field-experimental, a qualitative long-term expost and a cross-sectional household survey approach. The results revealed that social learning and avoiding the loss of trust were more relevant benefits of participatory flood management than acceptance building. The results suggest that stakeholder involvements should be more explicitly designed as tools for long-term social learning.
\end{abstract}

\section{Introduction}

In the last decade, stakeholder involvement in river management projects has become standard practice in Switzerland and in many European countries. A main reason for this paradigm shift away from purely engineer-based river management are new legal frameworks, such as the Swiss New Waters law (1991), the European Water Framework (2000) (Directive 2000/60/EC) and the European Union Directive on the Assessment and Management of Floods
(Directive 2007/60/EC). These regulations have demanded the involvement of all interested parties in the implementation of new water policies (Borowski et al., 2008), but have also stipulated that flood management be combined with ecological enhancement measures, which is equivalent to demanding that more room be provided for rivers (Hostmann et al., 2005; Zaugg, 2004; Junker et al., 2007; Buijs, 2009; Johnson and Priest, 2008). This has extended the complexity, and in particular the ambiguity, of the river management projects to the extent that conflict cannot be avoided when involving local stakeholders (Zaugg, 2004; Renn et al., 2011).

The principle of involving stakeholders in river management has since become widely accepted, yet there is still no clearly defined standard or agreement among experts as to the goals and the form of the stakeholder involvement (Höppner et al., 2010; Junker et al., 2007; Kuhlicke et al., 2011; Irwin, 2006; De Stefano, 2010). There is no explicit requirement in the EU Water Framework Directive (WFD) for active stakeholder involvement and, in the Public Participation Guidance Document no. 8 of the WFD (CIS, 2003), the qualitative aspects of such processes, such as co-ownership of the process design or opportunities for learning between stakeholders are mentioned, while goals are omitted. A baseline assessment of the quality of stakeholder involvement in Europe revealed that only a quarter of the countries adequately met such rather basic quality criteria (De Stefano, 2010).

Fiorino (1990) suggested a basic typology of stakeholder involvement rationales or goals, which differentiates 
between normative, instrumental, and substantial arguments. Normative arguments do not clearly refer to the goal of the involvement process but rather stress the significance of meaningful public participation; instrumental arguments primarily focus on achieving acceptance and support, and substantive arguments concentrate on improving the decision and promoting more extensive social effects, such as trust building or social learning (McDaniels et al., 1999). A review of risk communication literature and risk communication practice in Europe revealed that practitioners in the field of natural hazard management still mainly pursued instrumental goals, although recent research literature has emphasised the added value of substantive goals, such as social capital building (Leach and Sabatier, 2005), social learning (Muro and Jeffrey, 2008; Pahl-Wostl et al., 2007) and, more comprehensively, social capacity building (Kuhlicke et al., 2011; Hoeppner et al., 2010). Social capacity building is becoming more increasingly discussed as a key substantive goal for dealing with the increasing risk of natural hazards (UN/ISDR, 2006), successfully implementing integrated hazard management (BAPS, 2003), achieving social resilience against natural hazards (Adger et al., 2005) and, more generally, managing ecosystems sustainably (Leys and Vanclay, 2011). Social capacities describe the context-related abilities to decide and behave successfully in response to environmental stressors or environmental changes (Kuhlicke and Steinführer, 2010). In terms of individual stakeholders' social capacities, three categories are differentiated: knowledge capacities, motivational capacities and network capacities (Kuhlicke et al., 2011).

So far, there is relatively little systematic empirical evidence about the effectiveness of stakeholder involvement in terms of achieving substantial goals in the fields of hazard and natural resource management (Hophmayer-Tokich and Krozer, 2008; Muro and Jeffrey, 2008; Demeritt and Nobert, 2011; Höppner et al., 2012). One major reason for the lack of univocal evidence on this issue is the methodological difficulty in evaluating the effects of involvement processes. Experimental evaluation approaches suffer from uncertainties in terms of the temporal stability of the findings, interfering influence factors that cannot be controlled in long-term expost evaluations, and sample sizes that are often too small for robust statistical analysis.

There is a general consensus that stakeholder involvement contributes to achieving the instrumental goal of acceptance building: even among the wider (not directly involved) population (Hophmayer-Tokich and Krozer, 2008; Arvai, 2003). The benefit of stakeholder involvement for achieving substantial goals, however, is controversial and debated. This applies to all three categories of social capacity building.

In terms of knowledge building, dialogic forms of communication have been found to facilitate knowledge exchange and attitude changes (Höppner et al., 2012; Buchecker, 2008; Nobert et al., 2010; Howgate and Kenyon, 2009). The extent to which stakeholder involvement contributes to knowledge exchange and to the building of shared knowledge is, however, less clear. Recent research literature highlights the important role of participatory processes for social learning (Cundill et al., 2012; Biggs et al., 2011; Pahl-Wostl et al., 2008), although only a very limited body of evaluation studies on this issue exists, and these expectations have been neither clearly supported nor dismissed (Muro and Jeffrey, 2008). Whereas some descriptive case studies report a substantial increase of mutual understanding when stakeholders had exchanged their views during participatory processes (Mostert et al., 2008; Borowski et al., 2008), others observed a hardening, or even a polarisation, of the standpoints (Kolkman et al., 2007; Gray, 1997). Empirical studies using systematic repeated measurements have, however, provided some evidence that small-scale participatory processes enhance stakeholders' familiarity with others stakeholders' views and increase their consensus for future developments (Garmendia and Stagl, 2010; Buchecker et al., 2010). Furthermore, Mathevet et al. (2011) found, in a systematic survey study based on a mental model approach, that greater stakeholders' involvement in interactions within a water committee correlated with greater shared understanding of a risk management problem.

In terms of motivational capacities, dialogic and interactive forms of communication have been observed to enable participants' active engagement for risk prevention better than written or verbal communications (Moser, 2010). Furthermore, stakeholder involvement is assumed to enhance local ownership and increase local sense of responsibility (Butterfoss, 2006; Lachapelle and McCool, 2005). There is, however, very little empirical evidence that documents the degree to which participatory processes can raise participants' motivation to engage in risk preparedness or even their sense of responsibility for risk prevention. Lachapelle et al. (2005) report a number of successful examples in which participatory planning processes in the US have resulted in shared responsibility for the problem, the process, and the outcome of the process. Similarly, Heeb and Hindenlang (2008) describe how a stakeholder platform on the disputed management of an avalanche protection forest achieved a shared solution. Finally, experimental evaluations of participatory processes have provided some evidence that participatory processes increase stakeholders' motivation to participate in future participatory processes and to collaborate with other stakeholders for sustainable development (Höppner et al., 2007; Buchecker et al., 2010).

Considerably more research findings, but not necessarily more unambiguous evidence, can be found on the benefit of stakeholder involvement for creating network capacities. Across research fields it is widely expected that stakeholder involvement increases participants' trust (Kasperson et al., 1992; Slovic, 1993), builds social capital (Abelson et al., 2003; Butterfoss, 2006), and minimises conflicts (Bouwen and Taillieu, 2004; Joseph et al., 2008). Beierle and Konisky (2000) found, in an ex-post evaluation study based 
on document analysis, that participatory planning of environmental projects contributed considerably to conflict resolution between stakeholders in half of the investigated cases, but made a considerable contribution to trust building in only in a third of the investigated cases. Quasi-experimental studies in the context of landscape planning suggest that trust in planning agencies or authorities increases only if the participatory processes are of high quality (Höppner et al., 2007; Buchecker et al., 2010).

There is also some evidence that stakeholder involvement contributes to other aspects of social capital. An ex-post evaluation of landscape development concepts in Switzerland, which was based on project leaders' assessments, revealed that projects with stronger participatory components contributed to a higher mutual trust and understanding among the participants. Furthermore, the monitoring of watershed partnerships in the U.S. indicated a significant increase of stakeholders' reported mutual understanding and relationship quality during the process, but only after a period of $4 \mathrm{yr}$ of collaboration (Leach et al., 2002). Finally, Wagner and Fernandez (2009) detected notable decreases of some social capital components - in contrast to the dominant trend of increasing social capital - in their ex-post analysis of eight collaborative resource management projects: in three of the eight projects, mutual trust decreased during the collaborative process. The development of network capacities during involvement processes thus seems to be uncertain and sensitive to context and process conditions.

This study, however, assumes that (more) considerable uncertainty of the effects of stakeholder involvements on stakeholders' social capacities generally rests upon methodological limitations of the diverse evaluation methods and that a focus on single effects, particularly when measured with standardised formats, furthermore provides only weak evidence on the relative relevance of this effect. In this project we aimed to elicit the contribution of participatory flood management projects to stakeholders' social capacity building by triangulating the findings of three evaluation studies that were based on different measurement approaches. With this research design, we not only aimed at clarifying the contribution of stakeholder involvement to capacity building but also at differentiating the relative relevance of contributions to the three social capacity categories.

\section{Methods and results}

\subsection{Research design of the study}

To achieve our research goals, we have triangulated the findings of three independent evaluation studies on participatory planning processes of river revitalisation projects that we have conducted in recent years and which were based on different evaluation methods. Our study thus involved method and data triangulation (Junker et al., 2007). Triangulation is a term that was first used in American sociology and was defined by Delzin (1978) as a combination of methodologies in the study of one and the same phenomenon. The use of method triangulation is justified with the fact that one method can often not embrace the full complexity of a research object, and that through the mutual control of the methods, limitations of single methods can be recognised and compensated (Lamnek, 1988, p. 234). It provides a tool for cross validation (Erzberg and Prein, 1997), or at least an alternative to validation (Flick, 2002, p. 227), and it allows the achievement of broader and more profound insights (Lamnek, 1988, p. 234). The comparability of the evaluation studies was maximised in that they took place within the same legal and discursive context of Swiss river revitalisation and in the same period (2009-2011). Furthermore, in all three evaluation studies, an array of revitalisation projects were included and the effects were considered in an aggregated form. Finally, the effects on all three social capacity categories that are relevant for individual stakeholders and the effects in terms of instrumental goals were addressed in all of the evaluation studies.

In the following, the procedure, methods and results of the three evaluation studies will be presented in turn and will include a short account of the strengths and limitations of the respective method. After the presentation of the single studies, the findings will be compared and synthesised.

\subsection{Study 1: field-experimental (ex-ante/ex-post) evaluations of participatory planning processes of river revitalisation projects}

\subsubsection{Method}

This first study evaluated the effects of ongoing participatory projects on river revitalisation according to the research design of field experimental intervention research (e.g. Dwyer et al., 1993; Mosler and Tobias, 2000; Buchecker et al., 2010). Inherent in this methodology is that participatory processes can be considered to be an intervention aimed at changing attitudes towards environmental issues and related behaviour. We recorded the effect of the intervention using a repeated measurement with two largely identical standardised questionnaires that focused on items addressing stakeholders' reported social capacities, their assessment of characteristics of the involvement process, and their sociodemographic background. This questionnaire was distributed on two occasions in each involvement process: one at the beginning of the process, shortly after an advisory group had been constituted (first wave), and one after about one year of operation and after at least two meetings. Depending on the preference of the project leader we, or the project leader, either posted the questionnaires to the participants or handed them directly to the participants at group meetings. 


\subsubsection{Case studies}

We conducted our field experimental evaluations in six participatory river revitalisation projects (Menzel et al., 2013). The main criteria for selection of these case studies were that the project was at the beginning of the participatory planning phase and that the project was complex enough to affect a large number of stakeholders. By contacting leaders of the cantonal agencies responsible for water engineering and conducting two expert interviews, we identified seven eligible case studies and contacted the respective project leaders. The project leaders from six of the seven projects expressed willingness to collaborate in the research. The selected projects include three large and three medium-sized river revitalisation projects in four Swiss cantons. In all six case studies, regional stakeholders were involved in an advisory board that was established for each project in the planning process. The level of participation in the involvement processes can be ranked between consultative and collaborative participation (Biggs, 1989; EPA, 2012) because they included the goal of finding consensus solutions, but the room for negotiation conceded by the responsible agencies was rather limited.

\subsubsection{Sample}

We sent the questionnaires to all stakeholders involved in the advisory boards of the selected projects. These advisory boards consisted of between 6 and 40 people, depending on the size and complexity of the project. Representatives of the local authorities, affected land owners, nature protection organisations, and local fishery were involved in each advisory board, but not all group members attended every meeting and, in many cases, representatives of the involved interest groups were replaced by deputies. As a consequence, the number of participants who answered both questionnaires $(N=28)$ was considerable lower than the number of respondents in the first $(N=59)$ and the second waves $(N=92)$.

\subsubsection{Analysis}

The data were analysed statistically. To measure the effects of the stakeholder involvement processes, two complementary analyses were conducted. In one analysis the measurement of the effects was based on the comparison between the full datasets of the first and the second measurement waves. To account for uncertainty in terms of effects of the selfselection of the samples, only the mean values were compared under additional consideration of the standard error. In the second analysis, the effects were measured based on the data of the respondents who had filled in both questionnaires (T1 and T2). The differences between the mean values of the paired variables were tested with a $t$ test and effect sizes between the variables were compared based on the $t$ value.

\subsubsection{Strengths and limitations of the evaluation method}

The experimental approach allowed a systematic measurement of changes in stakeholders' reported social capacities through their involvement in the participatory process. External influences during the involvement process, with a period of some 12 months, can largely be excluded because no major and relevant natural or political event occurred. A limitation, however, is the small sample size and in particular the low response rate in the second measurement. The underlying self-selection effect has mainly implications on the data quality of the full sample analysis. Naturally, however, the paired sample can also not be considered to be an intact random sample because stakeholders with specific characteristics might have been motivated to fill in the questionnaire a second time. As the analysis of the paired sample is more reliable, this dataset was given priority when relative effects were compared. Another potential shortcoming of the approach is that stakeholders who had invested time in the involvement process may tend to overestimate the benefit of the process (Coglianese, 2001). Finally, effects measured immediately after stakeholder involvement processes might be influenced by momentary emotions and thus might not be stable over time (Buchecker et al., 2010).

\subsubsection{Results of the first study}

\section{Knowledge capacities}

Three dimensions of the knowledge capacity form of social capacities could be differentiated: knowledge building on the main topic or message of the project, knowledge building in terms of democratic learning or learning about involvement processes, and learning in terms of mutual understanding. Each dimension was measured with several items in both questionnaires. Whereas the repeated measurement of some items allowed us to measure the change of knowledge, some items were conceptualised for a comparison of expected and perceived effects.

The knowledge-building dimension was measured with two items in which respondents rated the importance of a list of potential goals (rating 7 goals using a 3-point scale) that thereby captured the two main messages addressed in the stakeholder involvement processes. In all the investigated river revitalisation projects, these two main messages were the necessity of both improving the flood management and combining it with an ecological enhancement of the river.

Respondents reported an increase between $\mathrm{T} 1$ and $\mathrm{T} 2$ in the perceived importance of improving the naturalness of rivers in both the analysis of the full sample (Table 1) and the paired sample (Table 2). Their perceived importance of flood prevention, however, slightly decreased in both sample analyses. We can therefore observe that the perceived importance of the two goals of river revitalisation converged. 
Democratic learning was measured with two items referring to the respondents' belief in the general value of the stakeholder involvement and their belief that stakeholder involvement increases participants' ability to engage in dialogues in the regions. Both items showed an increase in both sample analyses (Tables 1 and 2).

Finally, learning in terms of mutual understanding was measured with three items that addressed respondents' assessments of the success of the stakeholder involvement (1) in terms of achieving better understanding among the stakeholders, (2) in terms of convergence of their positions, and (3) in terms of agreement with the attitudes of other groups. In the first questionnaire, the first two items addressed the respondents' expected effects of the involvement process and, only in the second questionnaire, measured their experienced effects. With regard to the third item, the stakeholders were asked in the post-measurement to assess the change in their agreement. Therefore, this dimension was mainly measured in an ex-post manner.

In both analyses the stakeholders reported a slightly positive result of the involvement process in terms of both a better mutual understanding and convergence of stakeholders' positions (Tables 1 and 2). The assessed effect was, however, slightly lower than the expected effect at the beginning of the process. The analysis of stakeholder agreement with the positions of other groups revealed that the stakeholders perceived that more groups converge with their own position (agriculture, forestry, horsemen, fishery, nature protection) than diverge (building industry, local authorities). So, also in this respect, a certain learning process in terms of mutual understanding appears to have taken place during the stakeholder involvement.

\section{Motivational capacities}

There are three dimensions included in the motivational capacities form of social capacity: sense of responsibility, sense of ownership and cooperation.

Sense of responsibility was measured with stakeholders rating three items: participants' assessed importance of collaboration in the water management, participants' motives of welfare and participants' commitment to finding shared solutions. Ownership was operationalised by three items, with stakeholders rating how well the outcome provides a wellbalanced reflection of the concerns of the participants, the extent to which the process only served as a legitimisation of the project leaders' goals, and the amount of influence by participants on the outcome of the process. Cooperation was measured with two items: the assessed effect of stakeholder involvement for collaboration and the perceived cooperation of other stakeholders in the participatory process.

In the analysis of the full sample, the stakeholders rated the importance of collaboration in river management higher in the later phase of the stakeholder involvement process than they did in the early phase (Table 1). The rating of other items that measured the stakeholders' sense of responsibility, however, became lower during the involvement process, in both the analysis of the full sample and in the pairwise analysis (Tables 1 and 2). In particular, the assessment of participants' commitment to find a shared solution decreased substantially and significantly.

A similar trend was found in the items expressing the motivational capacities dimension. In both analyses the stakeholders reported their influence on the outcome of the process in the post-measurement as moderate and as lower than expected in the early phase of the process. The other two items that measured stakeholders' sense of ownership of the process showed a clear negative change during the process in both analyses. Stakeholders' (negative) perceptions that the participatory process was not an opportunity to achieve a shared solution, but rather a legitimation of project leaders' ideas, was found to increase substantially and significantly during the process.

\section{Network capacities}

The network capacities form of social capacity was considered in two dimensions: trust and conflict situation. Trust was measured with six items that addressed the stakeholders' relationships to the different levels of authorities, the planning agency and the least trusted stakeholder involved in the process.

The dimension of conflict situation was operationalised with three items. One item directly referred to the effect of the ongoing stakeholder involvement process on the conflict situation, one referred to the general effects of participatory processes on conflicts and collaboration, and the remaining item addressed the perceived conflict situation in the region.

The analysis of both the full sample and the paired sample revealed that stakeholders' trust in both the project leaders and the least trusted stakeholder decreased during the involvement process, whereas the trust in the planning agency increased (Tables 1 and 2). The results were less consistent in terms of trust building in the authorities of the different levels. The analysis of the paired sample found that trust in the cantonal and federal authorities increased substantially and significantly during the involvement process; the analysis of the full sample, however, showed that trust in cantonal and federal authorities decreased slightly, while trust in local authorities increased slightly during the involvement process.

The results on the conflict dimension appear to be more consistent. In both analysis samples, the perception that conflicts might increase due to stakeholder involvement was rated with a quite low mean value in the post-measurement, which was even substantially lower than the expected effect indicated by stakeholders in the pre-measurement. Correspondingly, both analyses found that the stakeholders' initial concerns that participatory processes generally tend to create conflicts decreased (at a low level) during the stakeholder involvement (Tables 1 and 2). Stakeholders' assessment of the 
Table 1. The respondents' perceived social capacities and acceptance of the project in the early (T1) and later (T2) phase of the stakeholder involvement process. Analysis of means of the full sample. Mean values T1 and T2 are in bold.

\begin{tabular}{|c|c|c|c|c|c|c|c|c|c|c|c|}
\hline $\begin{array}{l}\text { Capacity } \\
\text { type }\end{array}$ & Dimension & Item/Variable & Scale & $\begin{array}{l}\mathrm{N} \\
\mathrm{T} 1\end{array}$ & $\begin{array}{c}\text { Mean } \\
\mathrm{T} 1\end{array}$ & $\begin{array}{c}\text { StM } \\
\mathrm{T} 1\end{array}$ & $\begin{array}{l}\mathrm{N} \\
\mathrm{T} 2\end{array}$ & $\begin{array}{c}\text { Mean } \\
\mathrm{T} 2\end{array}$ & $\begin{array}{l}\mathrm{StM} \\
\mathrm{T} 2\end{array}$ & $\begin{array}{r}\Delta \\
\text { mean }\end{array}$ & $\begin{array}{r}\text { Glass's } \\
\Delta\end{array}$ \\
\hline \multirow{15}{*}{ 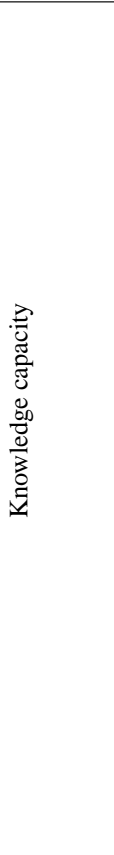 } & \multirow{2}{*}{ 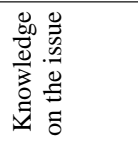 } & $\begin{array}{l}\text { Assessed importance } \\
\text { of improved naturalness }\end{array}$ & $1-3$ & 64 & 2.39 & 0.09 & 41 & 2.64 & 0.09 & 0.25 & 0.42 \\
\hline & & $\begin{array}{l}\text { Assessed importance of } \\
\text { improving flood prevention }\end{array}$ & $1-3$ & 60 & 2.57 & 0.08 & 41 & 2.51 & 0.10 & -0.06 & -0.08 \\
\hline & \multirow{2}{*}{ 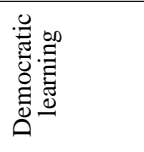 } & $\begin{array}{l}\text { Belief in stakeholder } \\
\text { involvement }\end{array}$ & $1-5$ & 91 & 3.99 & 0.09 & 58 & 4.12 & 0.12 & 0.13 & 0.14 \\
\hline & & $\begin{array}{l}\text { Belief that the ability for } \\
\text { dialogue improves through SI }\end{array}$ & $1-5$ & 92 & 4.04 & 0.30 & 58 & 4.12 & 0.14 & 0.08 & 0.07 \\
\hline & \multirow{11}{*}{ 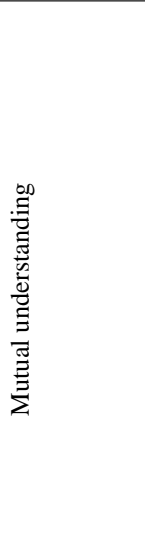 } & Expected/experience of convergence of positions & $1-5$ & 91 & 4.08 & 0.08 & 57 & 3.74 & 0.14 & -0.34 & -0.33 \\
\hline & & Expected/experienced better understanding of others' & $1-5$ & 91 & 4.07 & 0.09 & 58 & 3.97 & 0.09 & -0.10 & -0.10 \\
\hline & & Agreement with the position of agriculture & $-1-+1$ & & & & 57 & 0.04 & 0.09 & & \\
\hline & & Agreement with the position of forestry & $-1-+1$ & & & & 51 & 0.14 & 0.08 & & \\
\hline & & Agreement with the position of tourism & $-1-+1$ & & & & 27 & -0.11 & 0.12 & & \\
\hline & & Agreement with the position of fishery & $-1-+1$ & & & & 58 & 0.34 & 0.08 & & \\
\hline & & Agreement with the position of the building industry & $-1-+1$ & & & & 53 & -0.13 & 0.08 & & \\
\hline & & $\begin{array}{l}\text { Agreement with the position of } \\
\text { the environmental protection }\end{array}$ & $-1-+1$ & & & & 58 & 0.24 & 0.1 & & \\
\hline & & $\begin{array}{l}\text { Agreement with the position of } \\
\text { the local authorities }\end{array}$ & $-1-+1$ & & & & 58 & -0.05 & 0.08 & & \\
\hline & & $\begin{array}{l}\text { Agreement with the position of } \\
\text { the regional authorities }\end{array}$ & $-1-+1$ & & & & 58 & 0.12 & 0.07 & & \\
\hline & & $\begin{array}{l}\text { Agreement with the position of } \\
\text { the majority of the population }\end{array}$ & $-1-+1$ & & & & 55 & 0.02 & 0.07 & & \\
\hline \multirow{6}{*}{ 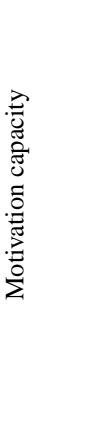 } & \multirow{3}{*}{ 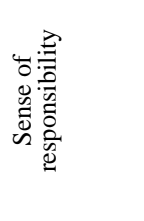 } & $\begin{array}{l}\text { Assessed importance } \\
\text { of future collaboration }\end{array}$ & $1-3$ & 58 & 2.0 & 0.09 & 47 & 2.28 & 0.10 & 0.28 & 0.39 \\
\hline & & $\begin{array}{l}\text { Belief that stakeholders look out } \\
\text { for their own interests }\end{array}$ & $1-5$ & 89 & 2.9 & 0.11 & 58 & 3.09 & 0.16 & 0.19 & 0.16 \\
\hline & & $\begin{array}{l}\text { Belief that stakeholders will } \\
\text { work hard to find a solution }\end{array}$ & $1-5$ & 90 & 4.22 & 0.10 & 57 & 2.70 & 0.14 & -1.52 & -1.45 \\
\hline & \multirow{3}{*}{ 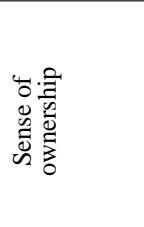 } & Expected/experienced influence of decision & $1-5$ & 89 & 3.34 & 0.14 & 58 & 3.10 & 0.14 & -0.24 & -0.22 \\
\hline & & $\begin{array}{l}\text { Expectation that outcome will } \\
\text { reflect interests of all stakeholders }\end{array}$ & $1-5$ & 90 & 3.58 & 0.11 & 58 & 3.41 & 0.13 & -0.17 & -0.19 \\
\hline & & $\begin{array}{l}\text { Expectation that the process will } \\
\text { only serve to legitimise the ideas } \\
\text { of the project leaders }\end{array}$ & $1-5$ & 82 & 2.45 & 0.13 & 46 & 3.22 & 0.18 & 0.77 & 0.62 \\
\hline \multirow{9}{*}{ 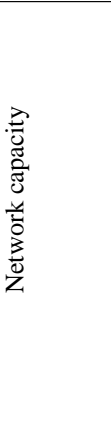 } & \multirow{6}{*}{$\stackrel{\vec{Q}}{\vec{E}}$} & Trust in cantonal authorities & $1-10$ & 90 & 6.62 & 0.22 & 45 & 6.65 & 0.31 & 0.03 & 0.01 \\
\hline & & Trust in municipal authorities & $1-10$ & 89 & 6.26 & 0.31 & 45 & 6.53 & 0.36 & 0.27 & 0.12 \\
\hline & & Trust in federal authorities & $1-10$ & 80 & 6.01 & 0.25 & 41 & 5.76 & 0.40 & -0.25 & -0.10 \\
\hline & & Trust in the planning agency & $1-10$ & 62 & 6.95 & 0.27 & 46 & 7.04 & 0.32 & 0.09 & 0.04 \\
\hline & & Trust in the project leaders & $1-5$ & 80 & 3.95 & 0.09 & 46 & 3.83 & 0.16 & -0.12 & -0.11 \\
\hline & & Trust in the least trusted stakeholder & $1-5$ & 79 & 2.73 & 0.10 & 45 & 2.49 & 0.15 & -0.24 & -0.23 \\
\hline & \multirow{3}{*}{ 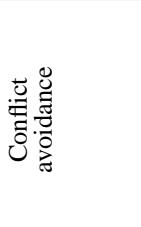 } & $\begin{array}{l}\text { Belief that the stakeholder } \\
\text { involvement can entail conflicts }\end{array}$ & $1-5$ & 92 & 2.17 & 0.10 & 58 & 2.07 & 0.14 & -0.10 & -0.09 \\
\hline & & $\begin{array}{l}\text { Expectation/experience that } \\
\text { the SI increases the conflicts }\end{array}$ & $1-5$ & 90 & 2.24 & 0.11 & 58 & 2.09 & 0.13 & -0.15 & -0.15 \\
\hline & & $\begin{array}{l}\text { Belief that in the region there } \\
\text { are many interest conflicts }\end{array}$ & $1-5$ & 88 & 2.42 & 0.13 & 58 & 2.43 & 0.16 & 0.01 & 0.01 \\
\hline \multirow{4}{*}{ 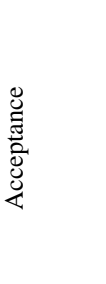 } & & I can support the project at this stage & $1-5$ & 80 & 4.16 & 0.14 & 47 & 3.94 & 0.18 & -0.22 & -0.17 \\
\hline & & $\begin{array}{l}\text { I expect that the project will } \\
\text { contribute to a wide acceptance of } \\
\text { the decision among the stakeholders }\end{array}$ & $1-5$ & 91 & 4.35 & 0.09 & 58 & 3.93 & 0.14 & -0.42 & -0.39 \\
\hline & & $\begin{array}{l}\text { The population will be contented } \\
\text { with the outcome of the process }\end{array}$ & $1-5$ & 89 & 3.39 & 0.11 & 58 & 3.07 & 0.16 & -0.32 & -0.27 \\
\hline & & $\begin{array}{l}\text { I will be contented with } \\
\text { the outcome of the process }\end{array}$ & $1-5$ & 85 & 3.65 & 0.06 & 57 & 3.67 & 0.14 & 0.02 & 0.02 \\
\hline
\end{tabular}


Table 2. The respondents' perceived social capacities and acceptance of the project in the early (T1) and later (T2) phase of the stakeholder involvement process. Analysis of means of the paired sample. Mean values T1 and T2 are in bold.

\begin{tabular}{|c|c|c|c|c|c|c|c|c|c|c|}
\hline $\begin{array}{l}\text { Capacity } \\
\text { type }\end{array}$ & Dimension & Item/Variable & Scale & $\mathrm{N}$ & $\begin{array}{c}\text { Mean } \\
\text { T1 }\end{array}$ & $\begin{array}{c}\text { StM } \\
\text { T1 }\end{array}$ & $\begin{array}{c}\text { Mean } \\
\text { T2 }\end{array}$ & $\begin{array}{l}\text { StM } \\
\mathrm{T} 2\end{array}$ & $\begin{array}{r}\Delta \\
\text { mean }\end{array}$ & $T$ value \\
\hline \multirow{6}{*}{ 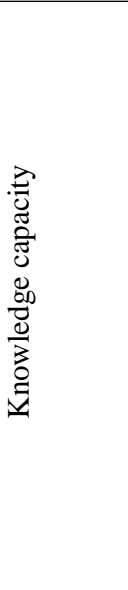 } & \multirow{2}{*}{ 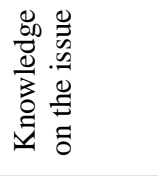 } & $\begin{array}{l}\text { Assessed importance of } \\
\text { improved naturalness }\end{array}$ & $1-3$ & 14 & 2.29 & 0.24 & 2.5 & 0.17 & 0.21 & -0.76 \\
\hline & & $\begin{array}{l}\text { Assessed importance of } \\
\text { improving flood prevention }\end{array}$ & $1-3$ & 12 & 2.67 & 0.19 & 2.58 & 0.19 & -0.09 & 0.56 \\
\hline & \multirow{2}{*}{ 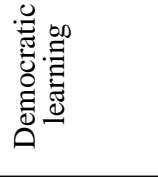 } & $\begin{array}{l}\text { Belief in stakeholder } \\
\text { involvement }\end{array}$ & $1-5$ & 28 & 4.04 & 0.20 & 4.14 & 0.17 & 0.10 & -0.57 \\
\hline & & $\begin{array}{l}\text { Belief that the ability for } \\
\text { dialogue improves through SI }\end{array}$ & $1-5$ & 28 & 3.86 & 0.24 & 4.04 & 0.24 & 0.18 & -1.22 \\
\hline & \multirow{2}{*}{ 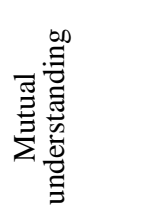 } & $\begin{array}{l}\text { Expected/experience of } \\
\text { convergence of positions }\end{array}$ & $1-5$ & 27 & 3.96 & 0.16 & 3.56 & 0.20 & -0.40 & 1.66 \\
\hline & & $\begin{array}{l}\text { Expected/experienced } \\
\text { better understanding } \\
\text { of others' }\end{array}$ & $1-5$ & 27 & 4.04 & 0.16 & 3.96 & 0.18 & -0.08 & 0.40 \\
\hline \multirow{6}{*}{ 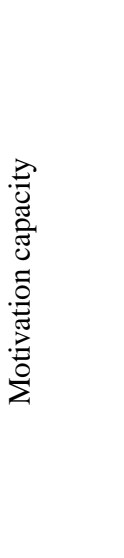 } & \multirow{3}{*}{ 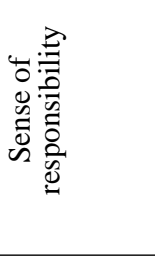 } & $\begin{array}{l}\text { Assessed importance } \\
\text { of future collaboration }\end{array}$ & $1-3$ & 14 & 2.07 & 0.17 & 2.00 & 0.18 & -0.07 & 0.25 \\
\hline & & $\begin{array}{l}\text { Belief that stakeholders look out } \\
\text { for their own interests }\end{array}$ & $1-5$ & 27 & 2.85 & 0.24 & 3.37 & 0.24 & 0.52 & -1.59 \\
\hline & & $\begin{array}{l}\text { Belief that stakeholders will } \\
\text { work hard to find a solution }\end{array}$ & $1-5$ & 27 & 4.04 & 0.24 & 3.00 & 0.22 & -1.04 & 2.61 \\
\hline & \multirow{3}{*}{ 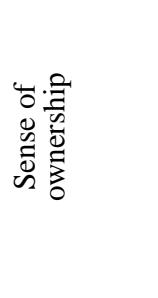 } & $\begin{array}{l}\text { Expected/experienced } \\
\text { influence of decision }\end{array}$ & $1-5$ & 27 & 3.26 & 0.21 & 2.93 & 0.21 & -0.33 & 1.67 \\
\hline & & $\begin{array}{l}\text { Expectation that outcome will reflect } \\
\text { interests of all stakeholders }\end{array}$ & $1-5$ & 27 & 3.37 & 0.23 & 3.30 & 0.19 & -0.07 & 0.40 \\
\hline & & $\begin{array}{l}\text { Expectation that the process will } \\
\text { only serve to legitimise the ideas } \\
\text { of the project leaders }\end{array}$ & $1-5$ & 21 & 3.05 & 0.23 & 3.38 & 0.29 & 0.33 & -0.76 \\
\hline \multirow{9}{*}{ 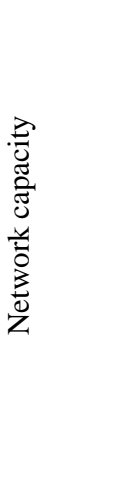 } & \multirow{6}{*}{$\stackrel{\overrightarrow{0}}{\vec{E}}$} & Trust in cantonal authorities & $1-10$ & 21 & 5.76 & 0.50 & 6.67 & 0.48 & 1.09 & -2.68 \\
\hline & & Trust in municipal authorities & $1-10$ & 21 & 5.81 & 0.57 & 5.86 & 0.61 & 0.05 & -0.12 \\
\hline & & Trust in federal authorities & $1-10$ & 18 & 5.39 & 0.49 & 6.00 & 0.66 & 0.61 & -0.98 \\
\hline & & Trust in the planning agency & $1-10$ & 20 & 7.30 & 0.47 & $\mathbf{7 . 5 0}$ & 0.48 & 0.20 & -0.45 \\
\hline & & Trust in the project leaders & $1-5$ & 21 & 3.95 & 0.19 & 3.71 & 0.29 & -0.24 & 1.42 \\
\hline & & Trust in the least trusted stakeholder & $1-5$ & 20 & 2.50 & 0.22 & 2.50 & 0.24 & 0.00 & 0.00 \\
\hline & \multirow{3}{*}{ 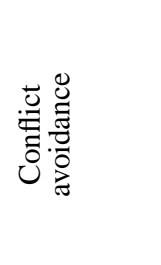 } & $\begin{array}{l}\text { Belief that the stakeholder } \\
\text { involvement can entail conflicts }\end{array}$ & $1-5$ & 28 & 2.21 & 0.21 & 2.00 & 0.19 & -0.20 & 0.88 \\
\hline & & $\begin{array}{l}\text { Expectation/experience that } \\
\text { the SI increases the conflicts }\end{array}$ & $1-5$ & 27 & 2.56 & 0.22 & 2.04 & 0.16 & -0.52 & 2.05 \\
\hline & & $\begin{array}{l}\text { Belief that in the region there } \\
\text { are many interest conflicts }\end{array}$ & $1-5$ & 27 & 2.15 & 0.21 & 2.22 & 0.22 & 0.07 & -0.28 \\
\hline \multirow{4}{*}{ 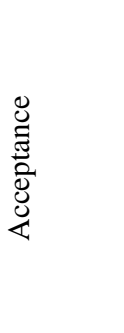 } & & I can support the project at this stage & $1-5$ & 21 & 3.90 & 0.33 & 4.05 & 0.29 & 0.15 & -0.44 \\
\hline & & $\begin{array}{l}\text { I expect that the project will } \\
\text { contribute to a wide acceptance of } \\
\text { the decision among the stakeholders }\end{array}$ & $1-5$ & 27 & 4.41 & 0.14 & 3.96 & 0.22 & -0.47 & 2.06 \\
\hline & & $\begin{array}{l}\text { The population will be satisfied } \\
\text { with the outcome of the process }\end{array}$ & $1-5$ & 27 & 3.19 & 0.21 & $\mathbf{3 . 0 4}$ & 0.23 & -0.15 & 0.64 \\
\hline & & $\begin{array}{l}\text { I will be satisfied with } \\
\text { the outcome of the process }\end{array}$ & $1-5$ & 23 & 3.52 & 0.12 & $\mathbf{3 . 8 3}$ & 0.22 & 0.31 & -1.78 \\
\hline
\end{tabular}


risk situation in the region showed no change between the pre- and the post-measurement in the full sample and a slight decrease in the paired sample.

\section{Acceptance building}

This effect of stakeholder involvement was measured with four items. A first item addressed stakeholders' support for the project. Two items directly operationalised acceptance building through the involvement process: one in regard to the stakeholders and one in regard to the regional population. Acceptance was measured in terms of stakeholders' satisfaction with the actual project.

Analysis of the two samples showed differences in the direction of the results, though at a low level, in two items. Analysis of the paired sample revealed that stakeholders' support for the project increased slightly and their satisfaction with the project increased considerably during the involvement process (Table 2). The analysis of the full sample revealed that stakeholders' support for the project slightly decreased, while their satisfaction with the project remained unchanged (Table 1). However, the expected acceptance of the project of both the affected population and (more substantially) the involved stakeholders decreased in both samples. Despite this trend of decreasing expected acceptance, the level of acceptance in the post-measurement remained clearly positive for all items.

\subsection{Study 2: survey-based evaluation of participatory river management projects in Switzerland}

\subsubsection{Method}

The second study evaluated the effects of stakeholder involvement on inhabitants' social capacities by eliciting their attitudes toward local river revitalisation projects, their assessment of stakeholder involvement in these projects, and their assessment of recent changes in regional social capacities. The measurement took place in the form of a standardised survey on ecological enhancement projects that was sent to a sample of 3000 households from the German-speaking population of Switzerland (Home et al., 2013).

The questionnaire focussed on ecological enhancement and included two photo-based choice experiments. One page of the questionnaire was dedicated to river revitalisation projects, which were defined as river management projects combining flood prevention and ecological enhancement of the river. On this page the respondents were asked to rate their agreement with statements related to river revitalisation using a 5-point scale.

\subsubsection{Sample}

Of the 3000 questionnaires sent, 2373 were delivered to a randomly selected sample of households and 492 questionnaires were sent to inhabitants of a rural area (Smaragd area) in which a specific project of ecological enhancement had been conducted. From an initial 2865 questionnaires successfully delivered, 437 completed questionnaires were returned (response rate $15.25 \%$ ) with 326 completed surveys returned from the random sample of the population and 111 returned from the Smaragd sample. The lower than expected response rate is possibly due to the complexity of the questionnaire, which was quite long and challenging. Sixty percent of the respondents live in country villages, which is above the proportion living in rural villages in Switzerland, although this is hardly surprising since the oversampling of the Smaragd sample is taken from a rural area. Fifty eight percent of the respondents were male and the majority (over 90\%) regularly engaged in the activity of walking.

\subsubsection{Analysis}

A key item of the questionnaire which stated that stakeholders were strongly involved in river revitalisation projects in their region was used to differentiate three groups: a group agreeing with the statement, a group not explicitly agreeing with the statement, and a group who indicated that they did not know about it. To assess the effect of stakeholder involvement on social capacities, the group members' agreement with social capacity-related statements were compared based on analysis of variance (ANOVA). The ANOVA procedure allows group differences to be tested under the condition of normal distribution and homogeneity of variance. Normal distribution was confirmed for all of the included variables (Kolmogorov-Smirnov), and the group differences of the few variables not showing homogeneity of variance (Lewene test) were tested based on the robust Welch test. The differences between the single subgroups were tested with the post hoc tests of Bonferroni and Tukey HSD. Group differences were assumed to indicate effects of stakeholder involvement on inhabitants' or stakeholders' social capacities. Respondents who reported that no river revitalisation project had been conducted in their region in the last $15 \mathrm{yr}$ were excluded from the analysis.

\subsubsection{Strengths and limitations of the evaluation method}

This evaluation method allows for a measurement of stakeholder involvement effects that reached beyond the involved stakeholders. The large sample size furthermore offers the basis for statistically reliable comparisons between different treatments. The most critical shortcoming of this approach lies in fact that the measurement of effects is based on a subjective assignment to the two compared groups. The respondents themselves assessed whether a considerable stakeholder involvement had taken place in their region. Measured effects might therefore also be influenced by co-variations of effect variables with perceived involvement. Furthermore, the direction of the influence is not absolutely clear. Finally, 
perceived involvement was operationalised with only one item, which limits the validity of the measurement.

\subsubsection{Results}

\section{Knowledge capacities}

In contrast to the field-experimental approach, only two dimensions of this type of social capacity could be measured. The measurement of knowledge on the issue was operationalised with two items: the sense of being informed on the river management projects in the region and the agreement with the principle of recent river management that more space should be left to rivers. Knowledge building, in terms of mutual understanding, was elicited with one item that addressed the recent convergence of positions between stakeholders representing agriculture and nature protection.

The analysis of variance revealed significant differences in terms of knowledge building between the two main subgroups: the subgroups that reported considerable stakeholder involvement and the subgroup that reported marginal involvement in river revitalisation planning in their region (Fig. 1). The respondents of the subgroup with considerable stakeholder involvement felt significantly better informed about the river management projects in their region and agreed substantially more with the principle of more space for rivers than the respondents of the subgroup with marginal stakeholder involvement. Furthermore, the mutual understanding of the stakeholders seems to have increased more in regions with considerable stakeholder involvement. Respondents from the subgroup with considerable stakeholder involvement reported significantly higher agreement (and positively instead of negatively) than the marginally involved subgroup that the positions of farmers and conservationists have converged in recent years.

\section{Motivational capacities}

The sense of responsibility dimension of motivational capacities was measured with an item to measure agreement with the statement that the responsibility for river management should be left to the experts. In terms of sense of ownership, a personal and a regional level were distinguished. Accordingly, one item addressed the personal relationship to the rivers in the region (the outcome of the projects), and a second item considered the region's capacity to control the development of its environment.

The analysis of variance identified significant differences between the two main subgroups in only one dimension of this type of social capacity (Fig. 2). The group differences in terms of sense of responsibility appeared to be very small, with the respondents from the subgroup with considerable stakeholder involvement agreeing even slightly more than those from the subgroup with marginal stakeholder involvement that river management should be left to experts. In contrast to the dimension of sense of responsibility, the subgroup differences in terms of the dimension sense of ownership appeared to be substantial. The personal relationship to regional rivers of respondents of the subgroup with considerable stakeholder involvement was found to be clearly higher than that of the respondents of the subgroup with marginal stakeholder involvement. However, only the difference between all three groups was found to be significant. The subgroup differences in terms of the regional level of sense of ownership appeared to be more pronounced. Here, the respondents of the subgroup with considerable regional stakeholder involvement showed a significantly higher agreement that the region had the capacity to control its environmental development.

\section{Network capacities}

Two dimensions of the network capacities type of social capacities were differentiated. A first dimension referred to trust in regional authorities and was measured with one item that addressed the respondents' increased confidence that the authorities in their region advocate a desirable spatial development of their region. A second dimension involved regional collaboration and was operationalised with an item highlighting increased collaboration by the regional stakeholder groups.

In terms of network capacities, the analysis of variance revealed systematic and highly significant subgroup differences, which indicated clear effects (Fig. 3). Respondents from the subgroup with considerable regional stakeholder involvement were found to express significantly higher trust in local authorities than respondents from the subgroup with only marginal regional stakeholder involvement. Accordingly, the respondents from the more participatory regions in terms of river management had a significantly more positive impression that the collaboration between the regional stakeholders had improved in recent years.

\section{Acceptance building}

This instrumental effect was measured in two dimensions. The personal acceptance of the river revitalisation projects was measured with one item that addressed respondents' satisfaction with the implementation of the projects in the region. A second item measured the more general acceptance of ecological enhancement projects and referred to the recent increase of such projects in the region.

The analysis of variance indicated systematic and substantial subgroup differences in terms of both dimensions of acceptance building (Fig. 4). The respondents from the subgroup with considerable stakeholder involvement were found to be significantly more satisfied with the river revitalisation projects in the region and were significantly more convinced that the regional populations' acceptance of ecological projects had increased in the last years than the 


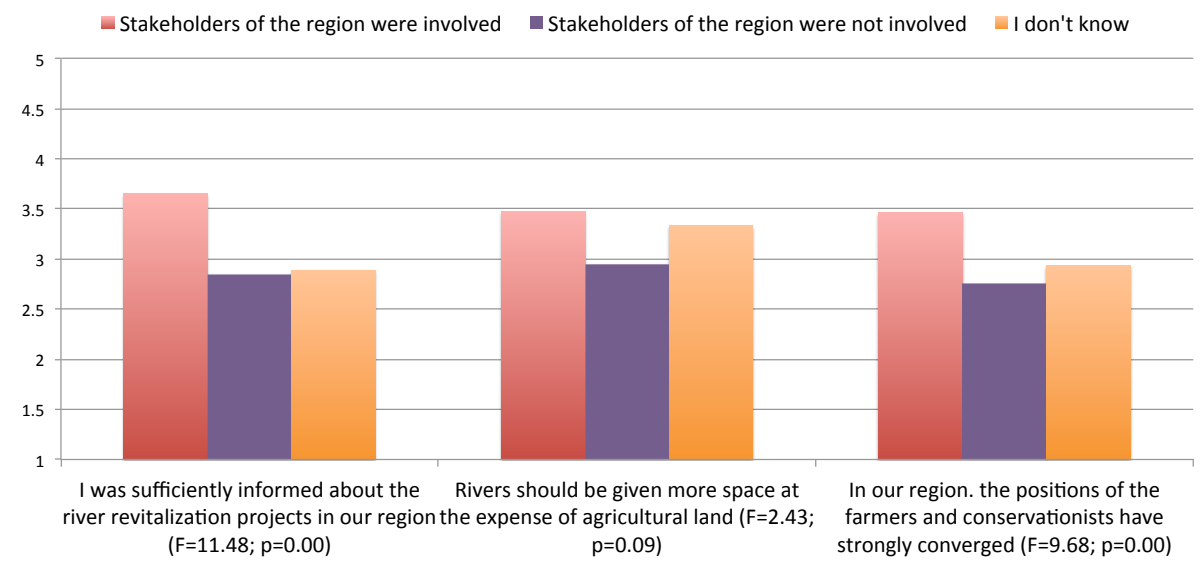

Fig. 1. Swiss inhabitants' agreement with statements related to their or their region's knowledge capacities, differentiated between groups with and without reported stakeholder involvement in their region. Comparison of mean values (ANOVA). $N=230$.

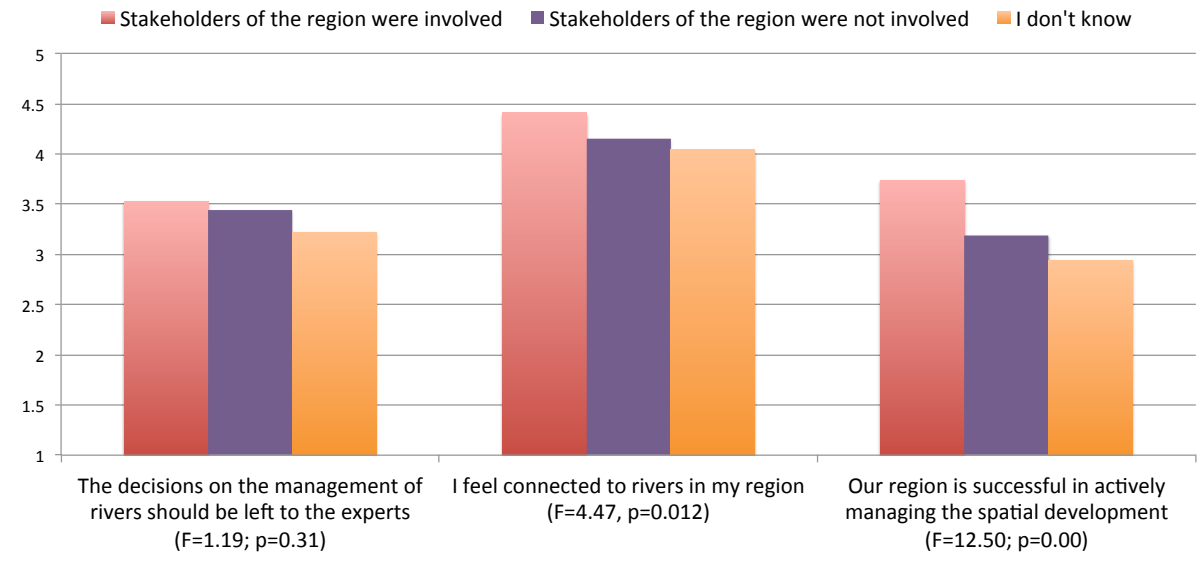

Fig. 2. Swiss inhabitants' agreement with statements related to their or their region's motivational capacities, differentiated between groups with and without reported stakeholder involvement in their region. Comparison of mean values (ANOVA). $N=230$.

respondents from the subgroup with marginal stakeholder involvement.

\subsection{Study 3: retrospective qualitative evaluation of completed river revitalisation projects}

\subsubsection{Method}

The third study evaluated the long-term effects of stakeholder processes of river revitalisation projects by conducting semistructured interviews with former members of the advisory boards of five successfully implemented projects (Menzel and Buchecker, 2013). The candidate river projects were selected according to the following criteria: the planning of a project had to have been finished at least $3 \mathrm{yr}$ prior to the study, the project had to be well documented, and the plans had to have been implemented. A further criterion for selecting a project was that it had to be in either the Germanor Rhaeto-Romanic-speaking area of Switzerland due to the language preferences of the investigators. A search identified 22 candidate cases and the final case studies were selected from those cases based on the criteria of some level of public interest and that the project leader was willing to collaborate. To meet the criterion of public interest, the planning process had to involve a wide range of stakeholders (with at least representatives from municipal agencies and from the fields of conservation, fisheries and landowners), and the restored river stretch had to be longer than $1 \mathrm{~km}$. The selected cases were five river engineering projects along the streams of Flaz, Kander, Langente, Thur, and Wyna. In these projects, regional stakeholders had been involved in form of advisory boards in the planning processes, which is a very similar form to that of study 1 . The level of participation was, however, less homogenous - ranging from a project (Kander) with very limited room for negotiation and thus with participation only slightly above the consultative level (Biggs, 1989; EPA, 2012), and projects (Flaz, Thur) with quite distinct collaborative characteristics. 


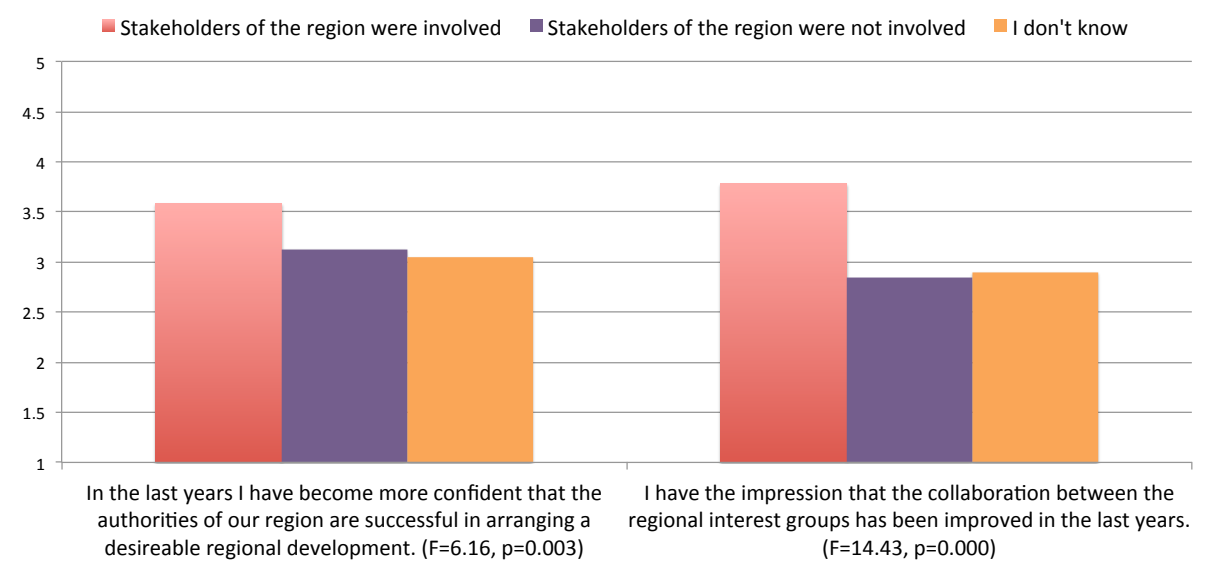

Fig. 3. Swiss inhabitants' agreement with statements related to their or their region's network capacities differentiated between groups with and without reported stakeholder involvement in their region. Comparison of mean values (ANOVA). $N=230$.

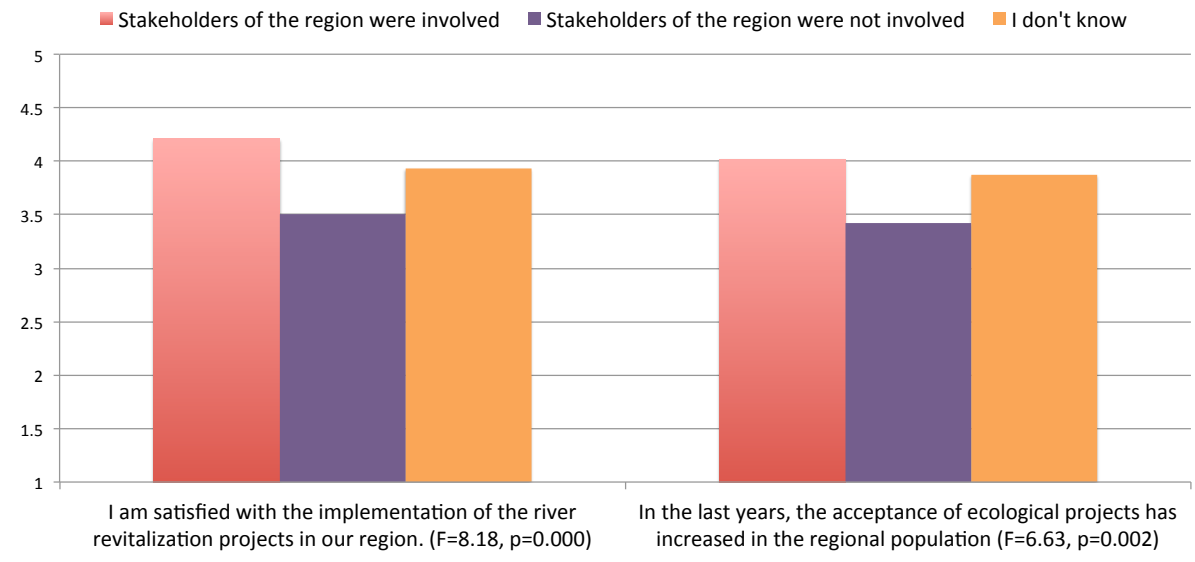

Fig. 4. Swiss inhabitants' agreement with statements related to their or their region's acceptance of ecological enhancement projects differentiated between groups with and without reported stakeholder involvement in their region. Comparison of mean values (ANOVA). $N=230$.

The interviews with the former advisory board members were guided by a list of key questions and optional subquestions that allowed a deeper consideration of interesting issues. The guideline addressed the role of the interviewee in the process, the characteristics of the planning process, context features, and the power of stakeholders to influence the process. Furthermore, the interviews addressed the effects of the participative/collaborative planning process on the interviewee, the other participants of the planning group, and those beyond the group, as well as exploring the characterising aspects of the relationships between the participants and their changes over time.

The interviews were all digitally recorded and transcribed. Two researchers developed the coding scheme in an iterative process that was based on a random sample of the interviews and on the research questions. Following the development of the coding scheme, one investigator coded the text in every interview and a second investigator coded a sample of the interviews to enhance reliability of the coding. In a final stage, the coded text was assigned to the three categories of social capacities.

\subsubsection{Sample}

A purposeful sampling strategy was applied (Patton, 1990; Coyne, 1997) to achieve a systematic and also comparable overview of the effects that the investigated involvement processes had on stakeholders' social capacities. For each case, five to six interviewees were selected from each of the five former advisory boards so that the following functions were represented: the authority in charge of the planning process, conservation (governmental or civil society organisations, $\mathrm{CSO}$ ), fisheries, landowners, and the municipalities. Furthermore, we preferred participants who had been continuously involved in the planning process. A total of 26 interviews were conducted with 25 male and one female interviewees, with an age range of approximately $45-65 \mathrm{yr}$. 


\subsubsection{Analysis}

The effects of the stakeholder involvements, classified according to the three categories (and their subdimensions) of social capacities, were assessed on the basis of their overall relevance in the interviews. The relevance of each category was evaluated by the number of interview partners who mentioned effects of the respective category and on the relative relevance attached by the interview partners to this effect category (expressed significance).

\subsubsection{Strengths and limitations of the evaluation method}

This evaluation approach allowed the measurement of stakeholder involvement effects that have emerged and continued after the implementation of the revitalisation projects. Certain social effects are expected to become manifest only after the project has been realised (Innes and Booher, 1999; Leach et al., 2002), whereas certain social effects may not endure far beyond the stakeholder involvement process (Buchecker et al., 2010). Another strength of the evaluation method is that the qualitative analysis reliably reveals the relevance and significance that stakeholders attach to the mentioned effects. Both strengths, however, may also involve shortcomings. As revitalisation projects often have a strong political component, there is no certainty that stakeholders did not answer some questions strategically. Furthermore, it is not possible to clearly differentiate between the effects of the stakeholder involvement and the effects of the successful implementation of the project. The findings may also be subject to the limitations of each stakeholder's memory. Finally, the systematic selection of the samples may have led to the neglect of effects perceived by involved stakeholder groups that have been less directly affected by the river revitalisations.

\subsubsection{Results}

The analysis of the interviews revealed the most relevant effects of stakeholder involvement on social capacity building. In the following, the main effects will be presented according to the three social capacity types.

\section{Knowledge capacities}

Learning was found to be the most relevant long-term effect of participatory planning of river revitalisation projects. Nearly all stakeholders emphasised that they and all other stakeholders had learnt a lot during these processes. The most often mentioned dimension of learning appeared to be issuerelated learning: learning about the benefits of nature-based river management in which more space is given to rivers. Even stakeholders who were strongly opposed to this form of river management at the outset confessed that they had become fully convinced of the value of this new strategy. More generally, stakeholders highlighted their learning about ecological aspects of river management and their increased ecological awareness and expressed appreciation at being able to benefit from the specialised knowledge of others. Increased awareness of flooding, however, was only mentioned by some governmental stakeholders.

A second learning effect that was often mentioned was learning how to interact and constructively collaborate, which can be assigned to the dimension of democratic learning. Many stakeholders admitted that they were more stubborn and determined in defending their interests at the beginning than at the end of the process, and that they had learnt to polarise less. Most stakeholders mentioned the heavy workload involved with participation in the process, but added that they have become convinced of its value. Project leaders stressed that they had learnt a lot about conducting participative processes, such as the desirability of showing more leadership, directly informing participants, and granting the process enough time for development.

The aspect of mutual learning, and in particular mutual understanding, was rather rarely explicitly expressed, although many stakeholders admitted that they became more sympathetic to environmental arguments during the process. Some conservationists also agreed that they increased their understanding of farmers' positions. Non-governmental stakeholders, however, often also emphasised the limitations of the convergence of positions and most spoke of compromise and agreement rather than of consensus.

\section{Motivational capacities}

The motivational effects of stakeholder involvement appeared to be of high relevance in most of the investigated projects. Especially in the completed projects with strong collaborative components, the stakeholders emphasised the development of a sense of ownership of the participatory process. A common topic was the existence of internal conflicts and internal fronts at the outset of the process, which turned into shared solutions and fronts against external project opponents in the later phases of the process. Stakeholders who were involved in less collaborative projects, however, considered the planning process to be something external and on which they had only marginal influence. Even in these cases, most stakeholders expressed a certain sense of ownership for the outcome of the planning process: some were proud of their project, some who were initially opposed became happy with the outcome, and some also mentioned that they felt now more connected to the river. In contrast to ownership, an increased sense of connection with the river management was hardly mentioned as an explicit outcome of the involvement process. Whereas, however, some stakeholders complained that they were not involved in certain meetings, no stakeholder mentioned that there were too many meetings. A project leader confirmed that stakeholders directly affected by the river management were very motivated to participate 
in the planning process, while the less affected stakeholders were not motivated to participate.

\section{Network capacities}

In the case studies, we found the most relevant network capacity building effects of the stakeholder involvement processes to be the mitigation of conflicts. Many stakeholders emphasised that the main benefit of the participatory process, and their main motivation for participation, was that the implementation of the project produced no losers. Unlike conflict mitigation, stakeholders seldom mentioned trust building as an effect of stakeholder involvement. Trust was only emphasised as an outcome of participatory planning processes in interviews with governmental stakeholders or when conflicts had occurred in the early phase of the process. In the cases where trust building was mentioned, it was often emphasised that it is a continuous process as trust was gradually created over time, although it deteriorates with changes of representatives. It was also mainly the governmental and municipal stakeholders who reported more generally about changes in relationships and some stakeholders even spoke of emotional moments when the meetings ended. Generally, however, relational effects of participatory planning on those stakeholders who had not been involved in the participatory process, or on the wider public, were found to be very limited. Improved relationships were often associated with easier collaboration: in terms of easier contacts and in terms of starting new collaborations at an advanced level. The issue of increased collaboration was never raised directly by stakeholders when asked about the effects of the stakeholder involvement. However, in two of the five cases, new institutions related to river management were initiated as a consequence of the participatory planning processes: a regional association for flooding and a yearly event of water days.

\section{Acceptance building}

There was a general consensus that the acceptance was much higher at the end of the stakeholder involvement than at the outset. The stakeholders, however, disagreed about the reasons for the increase in acceptance. For some, acceptance could not have been achieved without stakeholder involvement. Others considered other factors to be more relevant, such as the compensation payments to the affected landowners, a high proportion of funding through the federal state, a successful test of the measures against flooding, a reduction of original ecological goals or a positive reaction of the public after the implementation of the project. In this sense, non-governmental stakeholders in particular did not consider acceptance building as a very relevant result of the stakeholder involvement process.

\subsection{Synoptic view}

The comparison of the results reveals a higher similarity between the findings of the field-experimental and the longterm ex-post evaluations than with the study that was based on the cross sectional survey (Table 3). This is hardly surprising because the latter study assessed the opinions of a different target group: the Swiss inhabitants. The two evaluations that assessed the opinions of the involved stakeholders show a high agreement in terms of the highest ranked benefits in terms of social capacities (Table 3). All three evaluation approaches showed relatively low effects of stakeholder involvement processes on the stakeholders' sense of ownership and, in particular, on their sense of responsibility. Trust building was also ranked relatively low in all of the evaluation approaches. Particularly strong differences between the three studies emerged in terms of the effects on mutual understanding and on collaboration. In particular, the Swiss inhabitants expected much higher effects of stakeholder involvement on the social capacity dimensions than were measured in the ongoing processes. In contrast, stakeholder involvement seems to have a much lower effect on regional inhabitants' issuerelated knowledge than on the one of the directly involved stakeholders. Acceptance was found to build moderately in all of the evaluation studies. Generally, stakeholder involvement seems to have higher impacts on knowledge capacities than on acceptance building, while effects on network capacities and, in particular, on motivational capacities occur at a more moderate level.

\section{Discussion}

So far, only few studies have systematically evaluated the effects on stakeholders' social capacities of their involvement in participative processes related to the management of natural hazards or, more generally, of natural resources. Furthermore, most of these studies focussed on specific social capacities (Höppner et al., 2012; Demeritt and Nobert, 2011) and were based on one particular evaluation approach, so their results were subject to method-specific limitations (Lamnek, 1988). Accordingly, the significance and relative relevance of the diverse effect categories are still debated (Demeritt and Nobert, 2011; Muro and Jeffrey, 2008).

In this paper we compared the results of three evaluation studies on stakeholder involvements of river revitalisation projects in Switzerland that used different evaluation approaches. The results of this method and sample triangulation revealed consistent rankings of stakeholder involvement effects in terms of changes in stakeholders' social capacity categories. In the two evaluation approaches that only focussed on involved stakeholders, knowledge transfer, both in terms of the issue of river revitalisation as well as (somewhat less) democratic learning, appeared to be the most relevant effect of stakeholder involvements. The involved stakeholders 
Table 3. Ranking of the effects of the stakeholder involvement processes on the different social capacity dimensions according to the three evaluation approaches.

\begin{tabular}{|c|c|c|c|c|}
\hline \multicolumn{2}{|c|}{ Social capacities } & \multicolumn{3}{|c|}{ Evaluation approaches } \\
\hline Type & Dimension & $\begin{array}{c}\text { Field } \\
\text { experiment }\end{array}$ & $\begin{array}{l}\text { Cross sectional } \\
\text { survey approach }\end{array}$ & $\begin{array}{c}\text { Qualitative } \\
\text { long-term ex-post }\end{array}$ \\
\hline \multirow{3}{*}{ Knowledge capacity } & Knowledge on issue & 1 & 5 & 1 \\
\hline & Democratic learning & 3 & & 3 \\
\hline & Mutual understanding & 7 & 2 & 4 \\
\hline \multirow{2}{*}{ Motivational capacity } & Sense of responsibility & 9 & 7 & 9 \\
\hline & Sense of ownership & 8 & 6 & 5 \\
\hline \multirow{3}{*}{ Network capacity } & Trust & 6 & 4 & 7 \\
\hline & Conflict avoidance & 2 & & 2 \\
\hline & Collaboration & 5 & 1 & 8 \\
\hline Acceptance & Acceptance & 4 & 3 & 6 \\
\hline
\end{tabular}

changed their attitudes towards the new river management strategy and increased their skills in terms of consensus building and collaborative management. As they did not just change their attitude towards the project but also towards a more integrative management strategy, double loop learning seems to have taken place in some cases (Muro and Jeffrey, 2008). In this (limited) sense, the high expectations in terms of social learning through stakeholder involvement have been confirmed (e.g. Pahl-Wostl et al., 2008).

Unexpectedly, conflict avoidance, as one dimension of network capacity, appeared to be the second highest effect of stakeholder involvement in both studies. Correspondingly, in the evaluation based on a cross-sectional survey of the Swiss inhabitants, the related effect of improved collaboration between stakeholders was ranked highest. Conflict avoidance has so far hardly been considered in previous study as an effect of stakeholder involvement processes. Beierle and Konisky (2000) reported in their evaluation study about moderate effects of stakeholder involvements on conflict resolution, which is, however, not completely congruent with conflict avoidance. The often considered "acceptance building" is also not congruent with conflict avoidance as general acceptance of a project may not exclude single losers. Losers resulting from stakeholder involvements seem to be a major threat for stakeholders' network capacities.

In all of the evaluation studies, acceptance building only achieved a moderate ranking, although this is generally, and in particular among practitioners, considered to be the most relevant effect of stakeholder involvements (HophenmayerTokich and Krozer, 2008; Demeritt and Nobert, 2011). Acceptance, in the sense of not opposing the project, seems not to be a sufficiently ambitious outcome goal of an intensive stakeholder involvement. The stakeholders expect at least to be convinced of the outcome of the involvement process.

Most surprisingly, in all three of the evaluation studies, trust building appeared not to be a very relevant effect of the stakeholder involvements. In many studies, trust building has been considered to be a major added value of twoway communication, when compared to one-way communication (Höppner et al., 2012; Parker et al., 2007; Laurian, 2009). Recent studies, however, have highlighted the limitations of trust building through participatory processes (Höppner et al., 2007; Buchecker et al., 2010; Poortinga and Pidgeon, 2003) or even questioned the desirability of trust building for social capacity building (Terpstra et al., 2009) and, more generally, for democratic processes (Poortinga and Pidgeon, 2004; Parkins, 2010). They suggest that critical trust in the institutions, which includes a certain scepticism towards the motivations and also the competences of the authorities, rather than general trust, will increase the active role of the stakeholders in hazard management. Correspondingly, we found that stakeholders showed interest in establishing good relationships with the authorities as well as with the other stakeholder groups but did not aim for higher mutual trust. As the river revitalisation projects, as is the case in many other river management projects, challenge stakeholders' trust in the authorities in the first instance, the stakeholder involvement seems mainly to contribute to reproducing, rather than building, (critical) trust in the institutions.

In contrast to knowledge transfer, the effects in terms of mutual understanding, and in particular in terms of both dimensions of motivational capacities, all of which can be ascribed to the higher levels of social learning (Muro and Jeffrey, 2008), appeared to be rather low. The stakeholders involved in the ex-post interviews reported some better mutual understanding, but also emphasised the limitations of their understanding of others. While mutual learning was also assessed slightly positively in the experimental evaluation, stakeholders' assessments in terms of responsibility and ownership building appeared to be critical. The stakeholders only considered the participatory planning process as something of their own in cases with highly interactive 
involvement processes and, even in these cases, they left the responsibility for the flood management to the cantonal authorities. Furthermore, the inhabitants exhibited a clear reservation - in particular in terms of an increased sense of responsibility.

These low effects of stakeholder involvement in terms of stakeholders' motivational capacities are probably a consequence of the river revitalisation projects being initiated, and sometimes even pushed, by the cantonal authorities. In most of the projects, the influence of the stakeholders on the outcome of the decision process was too low for them to feel ownership of the process. In spite of the high numbers of stakeholder meetings, however, the motivation of the stakeholders to participate remained high throughout the planning process. So, although the results did not confirm the high expectations of stakeholder involvements in terms of ownership building (Lachapelle and McCool, 2005), they at least seem to have maintained stakeholders motivation to contribute to decision making in river management.

The study also revealed some methodological insights. The triangulation of results based on three different evaluation approaches provided a more comprehensive understanding about the effects in the target groups of stakeholder involvement. The results of the different evaluation approaches disclosed different facets of the same process. Recent philosophical literature has shown that differences between subjectivist and objectivist paradigms are smaller than previously assumed, and suggests that different methodological approaches can generally cooperate peacefully (Vaivio and Sirén, 2010). Different methodologies and methods combined in one study complement and challenge each other and thus improve the understanding of a phenomenon (Brown and Brignall, 2007). Moreover, trade-offs and limitations of different methods can be overcome by method triangulation (Abernethy et al., 1999, p. 25). Therefore, the comparison of the results also allowed for a more robust assessment of the relevance of diverse categories of effects in terms of social capacity building. Concordant results based on method triangulation imply a lower probability that the finding is wrong (Lamnek, 1988, p. 236) and offer a better chance of addressing a broader range of validity issues (Modell, 2005, p. 250). The rankings of effects based on the three methods may not be comparable, in a strict sense, as they do not refer to identical dimensions of the respective effect sizes. They do, however, address the subjectively perceived significance of the respective effects so that consistent rankings corroborate the findings, whereas discordant rankings, such as in terms of effects of trust building, can confirm assumed method-specific biases or else can reveal a more differentiated explanation of the reality (Lamnek, 1988, p. 236). In this sense the combination of the quantitative short-term experimental approach and the qualitative long-term ex-post approach facilitated a more reliable interpretation of the results. For example, the long-term ex-post interview data confirmed the assumption raised by Leach et al. (2002) that short-term measurements tended to over-estimate relational effects. On the other hand, ex-post interview data tend to overestimate ownership building through stakeholder involvements due to superposed effects of the successful implementation of the project. The survey-based data that measured the effects of stakeholder involvements on the inhabitants of the region showed only little similarity with the data from the other evaluation approaches. This is not surprising as these data refer to the mediated outreach process of the stakeholder involvement rather than to the dialogic involvement process. The data suggest that stakeholder involvement does not just increase regional inhabitants' acceptance of the outcome, as Arvai (2003) has found, but also contributes to improved trust in the regional authorities and to a more positive assessment of regional collaboration. Knowledge transfer, however, seems to be less relevant for the inhabitants than for the involved stakeholders.

In spite of the increased robustness of the results due to the method and sample triangulation, the findings of the study are subject to a number of limitations. A major point is the specific context in which this study has taken place that limits the ability to generalise the findings. All case studies that have been evaluated in this study are located within the context of Switzerland, in which stakeholders have a traditionally strong influence on regional politics and therefore also relatively high (critical) trust in authorities in comparison to other countries. Furthermore, all case studies investigated in this study referred to river revitalisation projects, which are distinctive and recent state interventions into traditional flood management strategies and thus involve a high regional resistance potential. Therefore, stakeholder involvement in purely hazard-management-related projects might be more efficient in terms of social capacity building and, in particular, in raising motivational capacities. As for the limitations of the evaluation methods, the qualitative long-term ex-post approach appeared to involve the least uncertainties as the complete protocols of the interviews with several stakeholders per case allow the researcher to identify most of the potential distortions. The data quality of the experimental approach was challenged by the limited response rate, and thus self-selection of the sample, and because the first measurement at the very outset of the process did not offer the optimal baseline data as the stakeholders did not have the necessary experience for a consolidated assessment. Future evaluation studies of stakeholder involvements may therefore best combine qualitative long-term ex-post measurements with experimental evaluations that start the first measurement after the first three meetings and also include non-involved stakeholders.

\section{Conclusions}

Recent literature has shown that practitioners mainly involve stakeholders in natural hazard projects with the 
goal of raising their acceptance and knowledge capacities (Höppner et al., 2012; Demeritt and Nobert, 2011). This study has shown that such involvement processes indeed best contribute to knowledge transfer, but that they also bear the potential, if well designed, to promote stakeholders' mutual understanding and their sense of ownership of the hazard management. These are most relevant for successful long-term strategies to make society more resilient against natural hazards. To accomplish this potential, it is necessary to explicitly pursue this goal and give stakeholders the opportunity to exchange and possibly agree on the understanding of their problem. Stakeholder involvement is recognised as necessary for successful implementation of complex projects, and this process is always time consuming. Therefore, it will be efficient to invest in the quality of the processes to achieve additional social capacity benefits that go beyond the project implementation. Future research should accompany such high-quality stakeholder involvement processes to validate the benefits and increase the understanding of social learning processes.

Edited by: C. Kuhlicke

Reviewed by: two anonymous referees

\section{References}

Abelson, J., Forest, P.-G., Eyles, J., Smith, P., Martin, E., and Gauvin, F.-P.: Deliberations about deliberative methods: Issues in the design and evaluation of public participation processes, Soc. Sci. Med., 57, 239-251, doi:10.1016/S0277-9536(02)00343-X, 2003.

Abernethy, M. A., Chua, W. F., Luckett, P. F., and Selto, F. H.: Research in managerial accounting: Lerning from others' experiences: "The scientist has no other method than doing his damnedest", Account. Financ., 39, 1-27, doi:10.1111/1467629X.00015, 1999.

Adger, W. N., Hughes, T. P., Folke, C., Carpenter, S. R., and Rockstrom, J.: Social-ecological resilience to coastal disasters, Science, 309, 1036-1039, doi:10.1126/science.1112122, 2005.

Arvai, J. L. : Using risk communication to disclose the outcome of a participatory decision-making process: Effects on the perceived acceptability of risk-policy decision, Risk Analysis, 23, 281-289, doi:10.1111/1539-6924.00308, 2003.

BAPS: KATARISK. "Katastrophen und Notlagen in der Schweiz", Bundesamt für Bevölkerungsschutz, Bern, Switzerland, 2003 (in German).

Beierle, T. C. and Konisky, D. M.: Values, conflict, and trust in participatory environmental planning, Journal of Policy Analysis and Management, 19,4, 587-602, doi:10.1002/15206688(200023)19:4<587::AID-PAM4>3.0.CO;2-Q, 2000.

Biggs, H., Breen, C., Slotow, R., Freitag, S., and Hockings, M.: How assessment and reflection relate to more effective learning in adaptive management, Koedoe - African Protected Area Conservation and Science, 53, 13 pp., doi:10.4102/koedoe.v53i2.1001, 2011

Biggs, S.: Resource-poor farmer participation in research: a synthesis of experiences from nine national agricultural research sys- tems. OFCOR comparative study paper, Vol. 3, International Service for National Agricultural Research, The Hague, 1989.

Borowski, I., Le Bourhis, J. P., Pahl-Wostl, C., and Barraque, B.: Spatial Misfit in Participatory River Basin Management: Effects on Social Learning, a Comparative Analysis of German and French Case Studies, Ecol. Soc., 13, 7, 2008.

Bouwen, R. and Taillieu, T.: Multi-party collaboration as social learning for interdependence: Developing relational knowing for sustainable natural resource management, J. Community Appl. Soc., 14, 137-53, doi:10.1002/casp.777, 2004.

Brown, R. and Brignall, S.: Reflections on the use of a dual-methodology research design to evaluate accounting and management practice in UK university central administrative service, Manage. Account. Res., 18, 32-48, doi:10.1016/j.mar.2006.07.001, 2007.

Buchecker, M.: Welche Ansprüche hat die Bevölkerung an ihre Wohnumgebung? in: Ballungsräume für Mensch und Natur, edited by: Tobias, S., Forum für Wissen 2008, WSL, Birmensdorf, 43-54, 2008 (in German).

Buchecker, M., Meier, C., and Hunziker, M.: Measuring the Effects of Consensus-building Processes with Methods of Intervention Research, Eur. Plan. Stud., 18, 259-80, doi:10.1080/09654310903491580, 2010.

Buijs, A. E.: Public support for river restoration. A mixedmethod study into local residents' support for and framing of river management and ecological restoration in the Dutch floodplains, J. Environ. Manage., 90, 2680-89, doi:10.1016/j.jenvman.2009.02.006, 2009.

Butterfoss, F. D.: Process evaluation for community participation, Annu. Rev. Publ. Health, 27, 323-340, doi:10.1146/annurev.publhealth.27.021405.102207, 2006.

CIS: Guidance Document No 8., Public Participation in Relation to the Water Framework Directive, Produced by Working Group 2.9 e Public Participation, Office for Official Publications of the European Communities, Luxembourg, 2003.

Coglianese, C.: Is satisfaction success? Evaluating public participation in regulatory policy making, Conference on evaluating environmental and public policy dispute resolution, programs and policies, Washington, DC, 8-9 March 2001.

Coyne, I. T.: Sampling in qualitative research. Purposeful and theoretical sampling; merging or clear boundaries?, J. Adv. Nurs., 26, 623-630, 1997.

Cundill, G., Cumming, G. S., Biggs, D., and Fabricius, C.: Soft Systems Thinking and Social Learning for Adaptive Management, Conserv. Biol., 26, 13-20, doi:10.1111/j.15231739.2011.01755.x, 2012.

Delzin, N. K.: The research act: A theoretical introduction to sociological methods, McGraw Hill, 1978.

Demeritt, D. and Nobert, S.: Models of 'good' risk communication for flooding and other water-related hazards: a critical review, KULTURisk WP5-report, UNESCO-IHE Institute for Water Education, Delft, available at: http://www.kulturisk.eu/results/wp5, last access: 8 May 2013, 2011.

De Stefano, L.: Facing the water framework directive challenges: A baseline of stakeholder participation in the European Union, J. Environ. Manage., 91, 1332-1340, doi:10.1016/j.jenvman.2010.02.014, 2010.

Dwyer, W. O., Leeming, F. C., Cobern, M. K., Porter, B. E., and Jackson, J. M.: Critical review of behavioral interventions to pre- 
serve the environment, Research since 1980, Environ. Behav., 25, 275-321, doi:10.1177/0013916593255001, 1993.

EC: Directive of the European Parliament and of the Council 2000/60/EC Establishing a Framework for Community Action in the Field of Water Policy, Official Journal 2000 L 327/1, European Commission, Brussels, 2000.

EC: Directive 2007/60/EC of the European Parliament and of the Council of 23 October 2007 on the assessment and management of flood risks, European Parliament, Official Journal 2007 L 288/27, European Commission, Brussels, 2007.

EPA (United States Environmental Protection Agency): Selecting the right level of public participation, available at: http://www.epa.gov/international/public-participation-guide/ Intro/Level/index.html last update: 26 July 2012.

Erzberg, C. and Prein, G.: Triangulation: validity and empirically based hypotheses construction, Qual. Quant., 31, 141-154, doi:10.1023/A:1004249313062, 1997.

Fiorino, D. J.: Citizen Participation and Environmental Risk - a Survey of Institutional Mechanisms, Sci. Technol. Hum. Val., 15, 226-43, doi:10.1177/016224399001500204, 1990.

Flick, U.: An introduction to qualitative research, 2nd Edn., Sage, London, 2002.

Garmendia, E. and Stagl, S.: Public participation for sustainability and social learning: Concepts and lessons from three case studies in Europe, Ecol. Econ., 69, 1712-1722, doi:10.1016/j.ecolecon.2010.03.027, 2010.

Gray, B.: Framing and reframing of intractable environmental disputes, Res. Negot. O., 6, 163-188, 1997.

Heeb, J. and Hindenlang, K.: Negotiating landscape in the Swiss Alps - Experience with implementation of a systemic landscape development approach, Mt. Res. Dev., 28, 105-109, 2008.

Home, R., Angelone, S., Bolliger, J., and Hunziker, M.: The influence of information on public preferences for ecological compensation areas in rural Switzerland, J. Environ. Manage., in review, 2013.

Hophmayer-Tokich, S. and Krozer, Y.: Public participation in rural area water management: experiences from the North Sea countries in Europe, Water Int., 33, 243-257, doi:10.1080/02508060802027604, 2008.

Höppner, C., Frick, J., and Buchecker, M.: Assessing psychosocial effects of participatory landscape planning, Landscape Urban Plan., 83, 196-207, doi:10.1016/j.landurbplan.2007.04.005, 2007.

Höppner, C., Buchecker, M., and Bruendl, M.: Risk communication and natural hazards, CapHaz-Net WP5 Report, WSL, Birmensdorf, 2010.

Höppner, C., Whittle, R., Brundl, M., and Buchecker, M.: Linking social capacities and risk communication in Europe: a gap between theory and practice?, Nat. Hazards, 64, 1753-1778, doi:10.1007/s11069-012-0356-5, 2012.

Hostmann, M., Buchecker, M., Ejderyan, O., Geiser, U., Junker, B., Schweizer, S., Truffer, B., and Zaugg Stern, M.: Wasserbauprojekte gemeinsam planen. Handbuch für die Partizipation und Entscheidungsfindung bei Wasserbauprojekten, Eawag, WSL, LCH-EPFL, VAW-ETHZ, 48 pp., 2005.

Howgate, O. R. and Kenyon, W.: Community cooperation with natural flood management: a case study in the Scottish Borders, Area 41, 329-340, doi:10.1111/j.1475-4762.2008.00869.x, 2009.
Innes, J. E. and Booher, D. E.: Consensus building and complex adaptive systems - A framework for evaluating collaborative planning, J. Am. Plann. Assoc., 65, 412-423, doi:10.1080/01944369908976071, 1999.

Irwin, A.: The politics of talk: coming to terms with the 'new' scientific governance, Soc. Stud. Sci., 36, 299-320, 2006.

Johnson, C. L. and Priest, S. J.: Flood risk management in England: A changing landscape of risk responsibility?, Int. J. Water Resour. D., 24, 513-525, doi:10.1080/07900620801923146, 2008.

Joseoh, C., Gunton, T. I., and Day, J. C.: Implementation of resource management plans: Identifying keys for success, J. Environ. Managem., 88, 594-606, 2008.

Junker, B., Buchecker, M., and Müller-Böker, U.: Objectives of public participation: Which actors should be involved in the decision making for river restorations?, Water Resour. Res., 43, W10438, doi:10.1029/2006WR005584, 2007.

Kasperson, R. E., Golding, D., and Tuler, S.: Social distrust as a factor in sitting hazardous facilities and communicating risks, J. Soc. Issues, 48, 161-187, doi:10.1111/j.15404560.1992.tb01950.x, 1992.

Kolkman, M. J., van der Veen, A., and Geurts, P. A. T. M.: Controversies in water management: Frames and mental models, Environ. Impact Assess., 27, 685-706, doi:10.1016/j.eiar.2007.05.005, 2007.

Kuhlicke, C. and Steinführer, A.: Social capacity building for natural hazards. A conceptual frame, CapHaz-Net WP1 Report, Helmholtz Centre for Environmental Research - UFZ and Johann Heinrich von Thünen Institute, Leipzig and Braunschweig, UFZ, Leipiz, Germany, available at: http://caphaz-net. org/outcomes-results, last access: 9 May 2013, 2010.

Kuhlicke, C., Steinführer, A., Begg, C., Bianchizza, C., Brundl, M., Buchecker, M., De Marchi, B., Tarditti, M. D., Hoppner, C., Komac, B., Lemkow, L., Luther, J., McCarthy, S., Pellizzoni, L., Renn, O., Scolobig, A., Supramaniam, M., Tapsell, S., Wachinger, G., Walker, G., Whittle, R., Zorn, M., and Faulkner, H.: Perspectives on social capacity building for natural hazards: outlining an emerging field of research and practice in Europe, Environ. Sci. Policy, 14, 804-814, doi:10.1016/j.envsci.2011.05.001, 2011.

Lachapelle, P. R. and McCool, S. F.: Exploring the concept of "ownership" in natural resource planning, Soc. Natur. Resour., 18, 279-85, doi:10.1080/08941920590908141, 2005.

Lamnek, S.: Qualitative Sozialforschung, Band 1 Methodologie, Psychologie Verlags Union, München, 1988.

Laurian, L.: Trust in planning: Theoretical and practical considerations for participatory and deliberative planning, Planning Theory \& Practice, 10, 369-391, doi:10.1080/14649350903229810, 2009.

Leach, W. D. and Sabatier, P. A.: To trust an adversary: Integrating rational and psychological models of collaborative policymaking, Am. Polit. Sci. Rev., 99, 491-503, doi:10.1017/S000305540505183X, 2005.

Leach, W. D., Pelkey, N. W., and Sabatier, P. A.: Stakeholder partnerships as collaborative policymaking: evaluation criteria applied to watershed management in California and Washington, J. Policy Anal. Manag., 21, 645-670, 2002.

Leys, A. J. and Vanclay, J. K.: Social learning: A knowledge and capacity building approach for adaptive co-management of contested landscapes, Land Use Policy, 28, 574-584, 
doi:10.1016/j.landusepol.2010.11.006, 2011.

Mathevet, R.,, Etienne, M. Lynam, T., and Calvet, C.: Water Management in the Camargue Biosphere Reserve: Insights from Comparative Mental Models Analysis, Ecol. Soc., 16, 43, 20 pp., 2011.

McDaniels, T. L., Gregory, R. S., and Fields, D.: Democratizing risk management: Successful public involvement in local water management decisions, Risk Analysis, 19, 497-510, doi:10.1111/j.1539-6924.1999.tb00424.x, 1999.

Menzel, S. and Buchecker, M.: Does participatory planning foster the transformation toward more adaptive socioecological systems?, Ecol. Soc., 18, 13, doi:10.5751/ES-05154-180113, 2013.

Menzel, S., Buchecker, M., and Schulz, T.: Forming social capital Does participatory planning foster trust in institutions?, J. Environ. Manage., in review, 2013.

Modell, S.: Triangulation between case study and survey methods in management accounting research, Manage. Account. Res., 16, 231-254, doi:10.1016/j.mar.2005.03.001, 2005.

Moser, S. C.: Communicating climate change: history, challenges, process and futuredirections, WIREs Climate Change, 1, 31-53, doi:10.1002/wcc.011, 2010.

Mosler, H.-J. and Tobias, R.: Die Organisation kollektiver Aktionen durch die Beeinflussung der individuellen Teilnahmeentscheidung, Kolner Z. Soziol. Soz., 52, 264-290, doi:10.1007/s11577000-0032-8, 2000 (in German).

Mostert, E., Craps, M., and Pahl-Wostl, C.: Social learning: the key to integrated water resources management?, Water Int., 33, 293304, doi:10.1080/02508060802275757, 2008.

Muro, M. and Jeffrey, P.: A critical review of the theory and application of social learning in participatory natural resource management processes, J. Environ. Plann. Man., 51, 325-44, doi:10.1080/09640560801977190, 2008.

Nobert, S., Demeritt, D., and Cloke, H.: Informing operational flood management with ensemble predictions: lessons from Sweden, Journal of Flood Risk Management, 3, 72-79, 2010.

Pahl-Wostl, C., Craps, M., Dewulf, A., Mostert, E., Tabara, D., and Taillieu, T.: Social learning and water resources management, Ecol. Soc., 12, 5, 19 pp., 2007.

Pahl-Wostl, C., Tabara, D., Bouwen, R., Craps, M., Dewulf, A., Mostert, E., Ridder, D., and Taillieu, T.: The importance of social learning and culture for sustainable water management, Ecol. Econ., 64, 484-495, doi:10.1016/j.ecolecon.2007.08.007, 2008.
Parker, D., Tapsell, S., and McCarthy, S.: Enhancing the human benefits of flood warnings, Nat Hazards, 43, 397-414; doi:10.1007/s11069-007-9137-y, 2007.

Parkins, J. R.: The problem with trust: Insights from advisory committes in the forest sector of Alberta, Soc. Natur. Resour., 23, 822-836, doi:10.1080/08941920802545792, 2010.

Patton, M. Q.: Qualitative Evaluation and Research Methods, 2nd Edn, Sage, Newbury Park, California, 1990.

Poortinga, W. and Pidgeon, N. F.: Exploring the dimensionality of trust in risk regulation, Risk Analysis, 23, 961-72, 2003.

Poortinga, W. and Pidgeon, N. F.: Trust, the asymmetry principle, and the role of prior beliefs, Risk Analysis, 24, 1475-1486, 2004.

Renn, O., Klinke, A., and van Asselt, M.: Coping with Complexity, Uncertainty and Ambiguity in Risk Governance: A Synthesis, Ambio, 40, 231-46, 2011.

Slovic, P.: Perceived risk, trust, and democracy, Risk Analysis, 13, 6, 675-682, doi:10.1111/j.1539-6924.1993.tb01329.x, 1993.

Terpstra, T.: Emotions, Trust, and Perceived Risk: Affective and Cognitive Routes to Flood Preparedness Behavior, Risk Analysis, 31, 1658-1675, doi:10.1111/j.1539-6924.2011.01616.x, 2011.

Terpstra, T., Lindell, M. K., and Gutteling, J. M.: Does communicating (flood) risk affect (flood) risk perceptions? Results of a quasi-experimental study, Risk Anal., 29, 1141-1155, doi:10.1111/j.1539-6924.2009.01252.x, 2009.

UN/ISDR: Hyogo framework for action 2005-2015: building the resilience of nations and communities to disasters, World conference on disaster reduction. Extract from the final report of the world conference on disaster reduction, 18-22 January 2005, Kobe, Hyogo, Japan. UN/ISDR, Geneva, 2006

Vaivio, J. and Sirén, A.: Insights into method triangulation and "paradims" in interpretative management accounting research, Manage. Account. Res., 21, 130-141, doi:10.1016/j.mar.2010.03.001, 2010.

Wagner, C. L. and Fernandez-Gimenez, M. E.: Effects of Community-Based Collaborative Group Characteristics on Social Capital, Environmental Management, 44, 632-645, doi:10.1007/s00267-009-9347-z, 2009.

Zaugg, M.: More Space for running waters: Negotiating institutional change in the Swiss flood protection system, GeoJournal, 58, 275-284, doi:10.1023/B:GEJO.0000017958.01882.77, 2004. 